- Bruce Bartholow Duncan

- M aria Inês Schmidt

\section{Chronic activation of the innate immune system may underlie the metabolic syndrome}

\author{
Social M edicine D epartment, School of M edicine, U niversidade Federal do
} Rio Grande do Sul, Porto Alegre, Brazil

\section{ABSTRACT}

CONTEXTO: The metabolic syndrome is characterized by a clustering, in free-living populations, of cardiovascular and diabetes risk factors generally linked to insulin resistance, obesity and central obesity. Consonant with the wellestablished inflammatory pathogenesis of atherosclerotic disease, the metabolic syndrome is now being investigated in relation to its inflammatory nature.

OBJETIVO: We present cross-sectional findings demonstrating that markers of inflammation correlate with components of the metabolic syndrome, and prospective findings of the ARIC Study indicating that markers of inflammation and endothelial dysfunction predict the development of diabetes mellitus and weight gain in adults. We present biological evidence to suggest that chronic activation of the innate immune system may underlie the metabolic syndrome, characterizing the common soil for the causality of type 2 diabetes mellitus and cardiovascular disease.

CONCLUSIONS: Better understanding of the role of the innate immune system in these diseases may lead to important advances in the prediction and management of diabetes and cardiovascular disease.

KEY WORDS: Inflammation. Cytokines. $\mathrm{N}$ on-insulin dependent diabetes mellitus. Cardiovascular disease. $O$ besity. Syndrome $X$

\section{........ INTRODUCTION}

Recent years have seen marked changes in our understanding of the risks for and pathogenesis of a series of chronic diseases, among them obesity, diabetes and atherothrombotic cardiovascular disease, which together constitute a major and growing cause of morbidity and mortality in adult populations around theworld. The remarkable similarity of the risk factors for coronary heart disease (CHD) and diabeteshasstimulated the search for a common pathophysiology for these conditions. ${ }^{1}$ Innumerable investigators are working to understand the clustering of these risk factorsin individuals. Therearevariousnames for these risk factors: syndrome $X_{1}{ }^{2}$ the insulin resistance syndrome, ${ }^{3}$ themultiplemetabolic syndrome, the plurimetabolic syndrome, or, as suggested by the World $\mathrm{H}$ ealth O rganization, ${ }^{4}$ simply the metabolic syndrome. The extent of the clustering has now been demonstrated in community-based populations of diverse ancestries around theworld. ${ }^{3,5-7}$ For instance, in the Atherosclerosis Risk in Communities (ARIC) Study, we demonstrated that $30 \%$ of the occurrence of five major syndrome abnormalities - hypertension, diabetes, high triglycerides, low high density lipoprotein-C (HDL-C), and high uric acid - aggregated in only $7 \%$ of the population. Thispercentage was three times that expected $(11 \%)$ by chance al one $(P<0.001)$.

O ne manner in which to express the tendency for any given factor to aggregate is the odds ratio of the association of that abnormality with the presence of two or more of the additional abnormalities. Asseen in Table 1, although variation was present across gender and ethnic groups, all of these five abnormalities were asso- ciated with important clustering of the others. Figure 1 shows important associations of the measurements of obesity, central obesity and insulin resistance (fasting insulin) with this clustering. Those with highest (top quintile) values of each of these three factors had considerably greater odds of presenting clusters of two, three, and especially four or more of these factors. ${ }^{7}$ As these analyses were adjusted not only for age, gender, ethnicity and ARIC Study center, but also for the levels of the other two factors, associations expressed in the graph for each are independent of the level of the other two. Additional studies havefound the presence of similar clustering in populations of diverse racial and ethnic composition throughout the world. ${ }^{6}$

Given theimportance of thesyndrome, and therecent demonstration of associations between inflammatory markers and syndrome elements, the purpose of this review is to integrate new knowledge concerning the possible interactions of inflammatory mediators with the syndrome.

$$
\text { BIOLOGICAL EVIDENCE }
$$

\section{Inflammation and Coronary H eart D isease}

Impressiveevidencehasaccumulated over the last decade that atherothrombotic cardiovascular disease is based fundamentally on inflammatory pathogenic mechanisms. Russell Ross, one of the main exponents of this hypothesis, recently and elegantly summarized theevidencefor theinflammatory nature of atherosclerosis, stating: "Thele sions of atherosclerosis represent a series of highly specific cellular and molecular responses that can best be described, in aggregate, as an inflamma tory disease" . ${ }^{8}$ The initial steps of atherosclerosis involve expression of leukocyte and endothelial 
cell adhesion molecules. This is followed by the involvement of monocytes, macrophages and innumerable cytokinesin the passage and accumulation of lipids. Late phases such as plaque rupture again involve macrophages and cytokineaction, which stimulate the release of matrix metalloproteinasesand other proteolytic enzymes. Additionally, vasoconstriction and spasm are in part induced by the action of pro-inflammatory cytokines, and an increased tendency toward coagulation results from actions of these same major pro-inflammatory mediators.

Several epidemiological studies investigating prospective associations between markers of inflammation and cardiac events have repeatedly demonstrated the power of such markers to pre dict futureevents. For example, sialic acid, which can beconsidered an integrated marker of thelevels of several acutephaseproteins, ${ }^{9}$ predictsC HD, with men with highest quartile sialic acid levels having a relative risk for cardiovascular mortality ${ }^{10}$ of 2.4 (2.0 to 2.8) and women 2.6 (1.9 to 3.6). Several studies have demonstrated the ca pacity of $C$ reactiveprotein (CRP), another acute phase protein, to predict events. Ascan be seen in data from the Physicians' Health Study ${ }^{11}$ in Figure 2, after adjustment for multiple other CHD risk factors, those with higher levels of $C R P$, inde pendent of thelevel of dyslipidemia, have greater risk of suffering an acute myocardial infarction. In diabetic patients, data from the ARIC Study ${ }^{12}$ demonstrate that diverse markers of inflamma tion, including an elevated leukocyte count, predict statistically significant increased risk. Those with leukocyte counts in thetop quartile (>7700 cells $/ \mathrm{mm}^{3}$ ) at baselinehad approximately double the risk of suffering an infarct over an ensuing mean 6.6 years of follow-up.

Investigation of mechanisms to explain these associations have centered on the three main direct mechanisms of CH D causation the atherosclerotic plaque, increased vascular tone (endothelial dysfunction) with resulting vasoconstriction and vasospasm, and thrombosis. H owever, if inflammatory mechanisms underlie the metabolic syndrome, then they could also cause CHD via the abnormalities of this syndrome. In this regard, wehave questioned whether the so-called "common soil" of CHD and diabetes could not be inflammatory in nature. ${ }^{13}$

\section{Inflammation and the Metabolic Syndrome: Cross-sectional Epidemiological Evidence}

Stimulated by the line of reasoning pre sented by some of the aboveevidence, and the striking similarity of risk factorsfor CHD and diabetes, we initiated an investigation of the role of inflammatory mediators in metabolic syndrome and diabetes in the ARIC cohort. ${ }^{14}$ In initial investigation of several correlations (Table 2), we noted several small to moderate-sized, but highly statistically significant correlations between markers of inflammation and abnormalities of the metabolic syndrome. Associations were most notable with body mass index (BM I) and triglycerides, and were somewhat stronger with triglycerides than with other abnormalities.

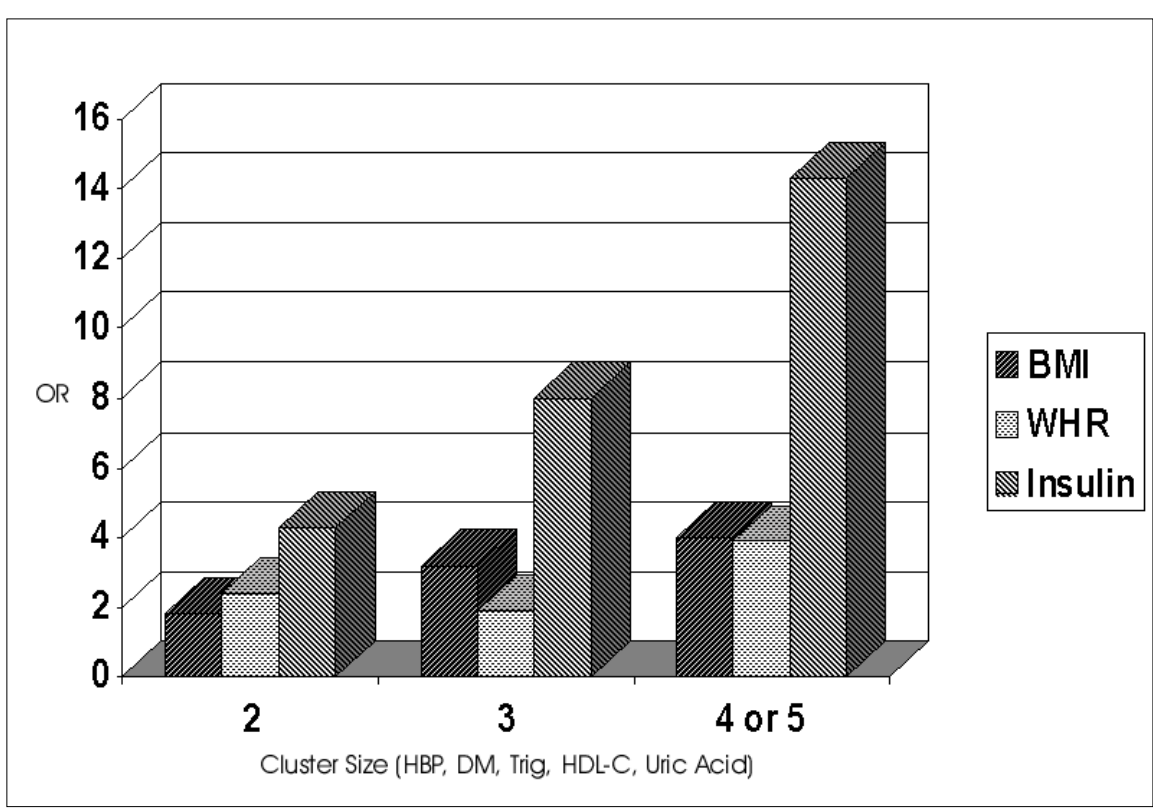

Figure 1. 0 dds of clustering of the CH D risk factors: hypertension (H BP), diabetes mellitus (D M ), high triglycerides (Trig), low high-density lipoprotein cholesterol (HDL-C) and uric acid by levels ( $5^{\text {th }}$ quintile vs. $1^{\text {d }}$ quintile) of fasting insulin, body mass index (BMI) and waist-hip ratio (WHR), in the Atherosclerosis Risk in Communities Study.

Table 1. Ethnic and gender-specific odds ratios of an individual presenting a cluster of two or more of the other four metabolic abnormalities (vs. none or only one abnormality), for those presenting a given abnormality. M en and women aged 45 to 64 of the ARIC BaselineSurvey, 1987 to 1989

\begin{tabular}{lllll} 
Presenting Abnormality & \multicolumn{4}{c}{ Odds Ratio } \\
\cline { 2 - 4 } & WM & WW & AAM & AAW \\
\hline Hypertension & $2.6 * * *$ & $4.0 * * *$ & $2.4 * * *$ & $2.4 * * *$ \\
\hline Diabetes & $3.4 * * *$ & $7.5 * * *$ & $1.6 * *$ & $2.0 * * *$ \\
\hline High Triglycerides & $5.0 * * *$ & $8.8 * * *$ & $5.4 * * *$ & $7.2 * * *$ \\
\hline Low HDL-C & $3.4 * * *$ & $7.8 * * *$ & $3.1 * * *$ & $2.7 * * *$ \\
\hline High Uric Acid & $2.6 * * *$ & $7.0 * * *$ & $2.3 * * *$ & $2.2 * * *$ \\
\hline
\end{tabular}

$* P<0.05 ; * * P<0.01 ; * * P<0.001 ;+0$ dds ratios obtained from multiple logistic models, controlling for age. The reference exposure category is that without the abnormality listed in the row: the reference end point category is that composed of individuals presenting at most one of the other four without the abnormality listed in the row; the reference end point category is that composed of individuals presenting at most one of the other four

\begin{tabular}{|c|c|c|c|c|c|c|c|}
\hline & WBC & ALB & FIB & TSSA & ORO & HAPT & alAT \\
\hline G LU & 0.06 & 0.09 & 0.06 & 0.04 & 0.04 & 0.03 & -.12 \\
\hline BM I & 0.05 & -.16 & 0.20 & 0.12 & 0.14 & 0.08 & -.03 \\
\hline W HR & 0.16 & 0.04 & 0.14 & 0.14 & 0.20 & 0.10 & -.01 \\
\hline IN S & 0.10 & 0.01 & 0.14 & 0.26 & 0.18 & 0.11 & .07 \\
\hline HDL-C & -.19 & -01 & -.12 & -.16 & -.26 & -.15 & -.08 \\
\hline TG & 0.16 & 0.08 & 0.02 & 0.40 & 0.22 & 0.12 & -.02 \\
\hline
\end{tabular}
$G L U=$ fasting serum glucose, $B M I=$ body mass index, $W H R=$ waist-to hip ratio, IN $S=$ fasting serum insulin, $H D L-C=$ high-density lipoprotein cholestero $T G=$ triglycerides, $W B C=$ white blood cell count, $A B B=$ albumin, $F I B=$ fibrinogen, $T S S A=$ total serum sialic acid, $O R O=$ orosomucoid, HAPT correlation coefficients $>0.02$, and in the sub-sample $>0.08$, are statistically significant $(P<0.05)$ : Reproduced ${ }^{24}$ with permission. 
Similar findingshad been reported previously by Pickup and C rook, ${ }^{15}$ in a small clinical sample of patients with type 2 diabetes. Yudkin ${ }^{16}$ took this investigation one step further, in a relatively small sample, correlating a Z-score based on the levels of several metabolic syndrome abnormalities with a Z-score calculated on levels of various acutephaseresponseproteins(Figure 3). A highly significant correlation $(r=0.59, P<0.001)$ was found. A morerecent demonstration of this association in a larger, freeliving population comes from the Insulin Resistance Atherosclerosis Risk (IRAS) Study. ${ }^{17}$ H ere(Figure4), Festa et al. demonstrated amonotonic increasein CRP levelswith the presence of an increasing number of metabolic syndrome abnormalities.

It isimportant to note that some of thelargest associations with inflammatory markers are

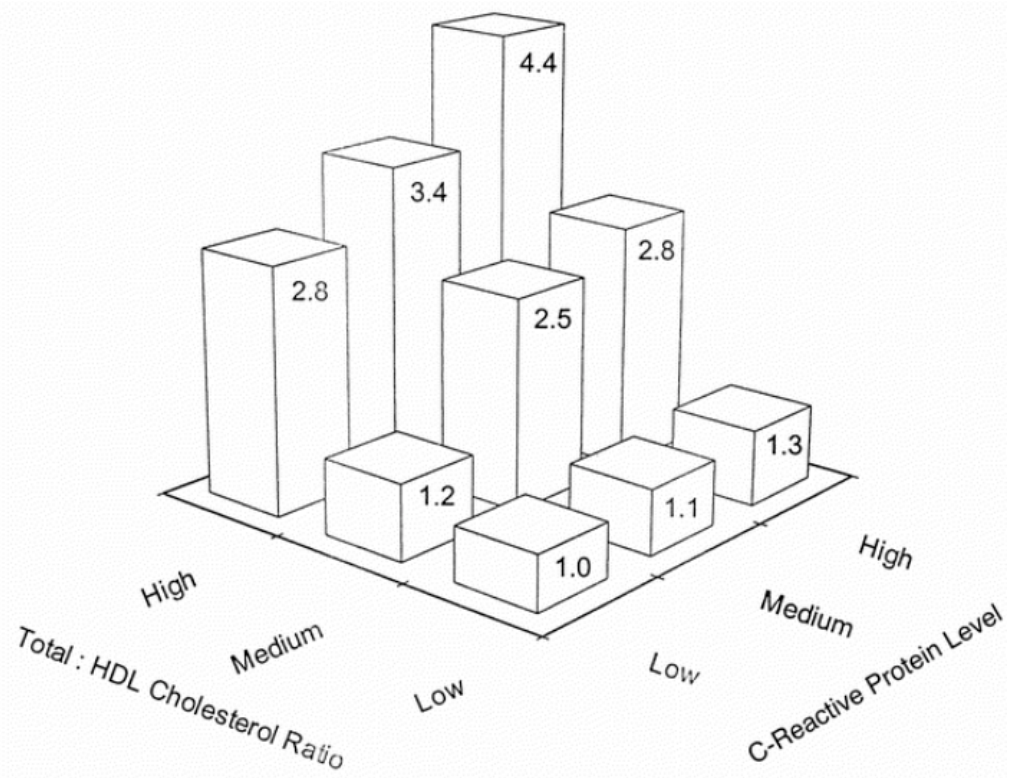

Figure 2. Relative risk of a future myocardial infarction as a function of baseline levels of $\mathrm{C}$-reactive protein and the total cholesterol-to-H D L-C ratio. Ridker PM . Evaluating N ovel Cardiovascular Risk Factors. Can We Better Predict H eart Attacks? Ann Intern M ed 1999;130:933-37. Reproduced ${ }^{11}$ with permission.

Table 3. Relative odds ${ }^{+}$(comparing extreme quartiles) of developing diabetes mellitus for

markers of inflammation in white and African-American men and women followed for an average of 7 years in the Atherosclerosis Risk in Communities Study, 1987-1998

\begin{tabular}{lcccccc} 
& \multicolumn{2}{c}{ Model 1 } & & \multicolumn{2}{c}{ Model 2 } \\
\cline { 2 - 3 } \cline { 5 - 6 } Marker & OR & $\mathbf{9 5 \%} \mathbf{C l}$ & & OR & $\mathbf{9 5 \% ~ C l ~}$ \\
\hline W hite cells, $1000 / \mathrm{mm}^{3}$ & 1.9 & 1.6 to 2.3 & & 1.5 & 1.3 to 1.8 \\
Low serum albumin, $\mathrm{g} / \mathrm{I}$ & 1.3 & 1.0 to 1.5 & & 0.98 & 0.80 to 1.2 \\
Fibrinogen, $\mathrm{g} / \mathrm{I}$ & 1.2 & 1.0 to 1.5 & & 0.93 & 0.77 to 1.1 \\
\hline
\end{tabular}

as determined in logistic regression: $O R=0 d d s$ ratio: $C l=$ confidence interval: Model 1: adjusted for age gender race and center, baseline glucose family history of diabetes, physical activity and pack-years of cigarette smoking; M odel 2: adjusted additionally for body mass index and waist-to-hip ratio; Adapted ${ }^{14}$ with permission.

Table 4. Relative odds' of developing diabetes mellitus for those with values above the median for sialic acid and three acute phase proteins in 610 white and African-American men and women followed for an average of 4.6 years in the Atherosclerosis Risk in Communities Study, 1987 to 1996

\begin{tabular}{|c|c|c|c|c|c|c|}
\hline \multirow[b]{3}{*}{ Marker } & \multicolumn{2}{|c|}{ Model 1} & \multicolumn{4}{|c|}{ Model 2} \\
\hline & \multirow[b]{2}{*}{ OR } & \multirow[b]{2}{*}{$95 \% \mathrm{Cl}$} & \multicolumn{2}{|c|}{ All Cases } & \multicolumn{2}{|c|}{ First 3 years ${ }^{++}$} \\
\hline & & & OR & $95 \% \mathrm{Cl}$ & OR & $95 \% \mathrm{Cl}$ \\
\hline Sialic acid & 3.7 & 1.4 to 9.8 & 2.8 & 1.0 to 8.1 & 4.4 & 1.1 to 16.8 \\
\hline O rosomucoid & 7.9 & 2.6 to 23.7 & 7.1 & 2.1 to 23.7 & 7.9 & 1.9 to 32.3 \\
\hline$a_{1}$-antitrypsin & 1.0 & 0.4 to 2.4 & 1.1 & 0.4 to 2.8 & 1.8 & 0.6 to 4.9 \\
\hline Haptoglobin & 1.7 & 0.7 to 4.0 & 1.6 & 0.6 to 4.1 & 2.1 & 0.7 to 6.0 \\
\hline
\end{tabular}

+ As determined in logistic regression modeling; ++ Analyzing only cases detected at ARIC Visit 3, encompassing, approximately the first three years of follow-

up; $O R=$ odds ratio; $95 \% \mathrm{Cl}=95 \%$ confidence interval; Model 1: adjusted for age, gender, ethnicity, atherosclerosis case-control status, fasting plasma glucose
family history of diabetes and smoking status; Model 2: adjusted additionally for body mass index and waisto-hip ratio; Reproduced ${ }^{14}$ with permission.

seen with BM I. In fact, adipocytes, especially in the obese, have been shown to produce a wide range of pro-inflammatory cytokines and other mediators, including leptin, TN F a, IL-6 and perhaps PAI- $1 .{ }^{18,}{ }^{19} \mathrm{M}$ ohamed-Ali et al. ${ }^{20}$ quantified post-prandial production of IL-6 in sub-cutane ous fat, with results suggesting that a large fraction of bodily production of this cytokine in the post-prandial period comes from adipocytes

A logical question, given these findings, is: which come first, inflammatory markers or the metabolic syndrome? D emonstration of thepresence of a chronic inflammatory state prior to the development of syndrome elements, as has been amply shown for CHD, would strengthen the hypothesisthat a systemic inflammatory response contributes to the development of thesyndrome.

\section{Inflammation and the Metabolic Syndrome Prospective Epidemiological Evidence}

To initiate investigation of the temporal re lationship between inflammatory markers and syndrome abnormalities, we chose to study incident diabetes. ${ }^{14}$ We followed over 12000 men and women aged 45-64 yearsin theARIC Study for approximately 8 years, during which over 1300 new cases of diabetes were ascertained. As can be seen in Table 3, those with elevations of 3 markers of inflammation, after adjustment for several risk factors for diabetes (M odel 1), had significantly increased risk of developing diabe tes. After further adjustment for BM I and W H R (M odel 2), the association for albumin and fibrinogen was no longer present. Those, however, with leukocyte counts in the highest quartile had a $50 \%$ increased risk of developing diabetes. M oreover, as will be discussed below, the risk shown in M odd 1 may be closer to the true situation, as M ode 2 may be over-adjusted.

Sialic acid and three acute-phase proteins had previously been measured in a subset of approximately 600 of these individuals. 0 ver an average of 4.9 years, 33 new cases of diabetes were ascertained in this subset. Comparing high with low levels of these markers at baseline with the development of diabetesin multiply adjusted analyses, wefound that sialic acid and, to an even greater extent, the acute-phase protein orosomucoid predicted the development of diabetes (Table 4). Interestingly, associations were strongest over the first follow-up period.

Given that obesity is a central element of the metabolic syndrome, we next investigated the possibility that elevation in inflammatory markerscould also predict weight gain. ${ }^{21} \mathrm{~A}$ largeweight gain was defined as one greater than the $90^{\text {th }}$ percentile for the cohort over the threeyear period following baselineexamination, or approximately $6 \mathrm{~kg}$. The risk of having a large weight gain, after 
multipleadjustment, including baselineBM I, was again predicted by high levels of several inflammatory markers, most notably for fibrinogen (Figure 5). In fully adjusted analyses, those with baseline fibrinogen values in the highest quartile had $65 \%$ greater odds of having a large weight gain over theensuing 3 yearsthan thosewith valuesin thefirst quartile.

\section{The Innate Immune System}

Thesefindingsled us to seek potential explanations. An attractive one has been offered by Pickup and Crook. ${ }^{22}$ These investigators, noting that Type 2 diabetes mellitus is characterized by an immuno-metabolic profile consistent with activation of the innate immune system, proposed that Type 2 diabetes might be a disease of this system.

Thehuman immunesystem isbased on both acquired (specific) and innate (relatively non-specific) immunity. Acquired immunity is based on cellular processing, over a period of days, of unique antigens with subsequent production of antibodiesand other immunemoleculesspecific to them. Innate immunity, on the other hand, is "hard wired", generating an immediateresponseto perceived threats to bodily integrity. Innate defense mechanismsincludephysical barriers, solublefactorssuch asthecomplement cascade, chemokines and cytokines, as well as white cells such as monocytes, macrophagesand neutrophils, whose bactericidal action, although related to acquired immunemechanisms, is distinct from that of the $T$ and $B$ cells of acquired immunity. ${ }^{23}$

All of the components of the inflammatory response and of endothelial dysfunction which have been linked to cardiovascular disease, the metabolic syndrome and diabetes are, in one form or another, related to this innate immune system. Somecomponentsindicatethepresence of activators of the system (infections such as Chlamydiaand cytomegal ovirus, cigarettesmoking); others its molecular mediators ( $C$ reactive protein, serum amyloid A, sialic acid); and still others, downstream results of its activation (adhesion molecules such as ICAM, matrix metalloproteinases, and vasoconstriction).

Theinnatesystem, although phylogenetically more primitive than the acquired, has a funda mental rolein human survival. I ts defensemechanismscan beviewed asbasically antimicrobial and hemostatic. They are orchestrated primarily by cytokines, polypeptides produced by many cells, particularly monocytes and macrophages, whose main function isintercellular signaling. M ost proinflammatory cytokines originate in multiplecell typesand havemultipletarget cellsand functions, with autocrine(samecell), paracrine(neighboring cell) and epicrine (distant cell) actions. Among

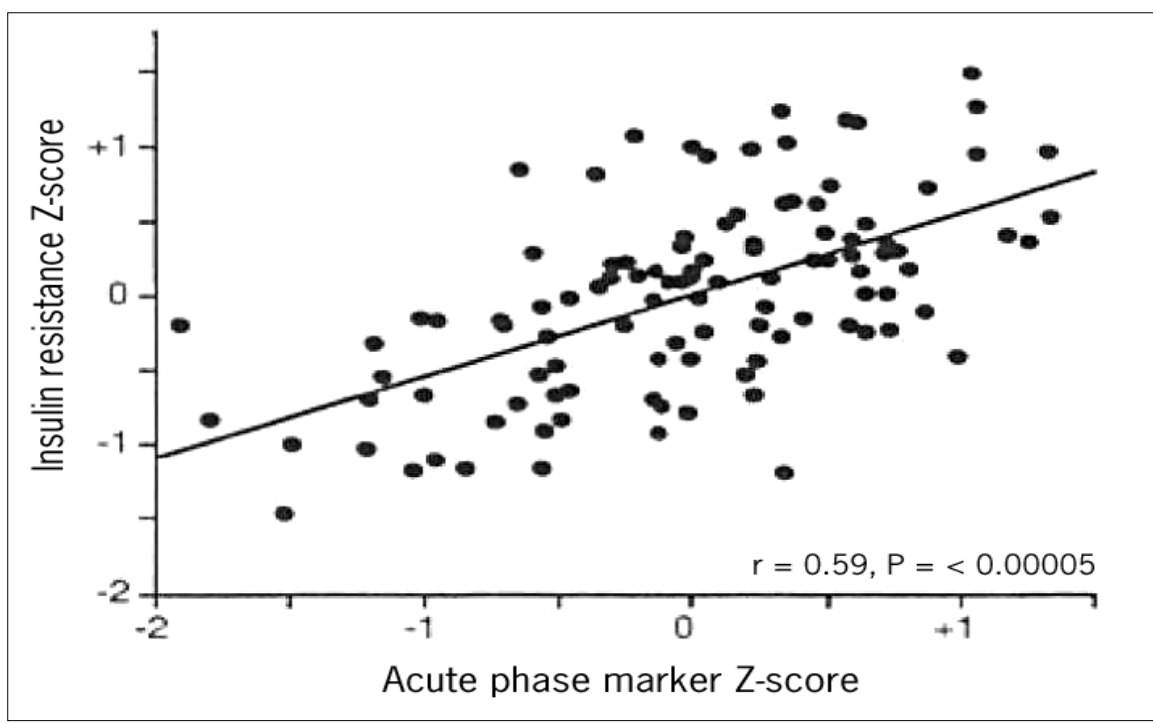

Figure 3. Association of the insulin resistance syndrome with the acute phase reaction. Yudkin JS, et al. C-reactive Protein in $\mathrm{H}$ ealthy Subjects. Associations with O besity, Insulin Resistance, and Endothelial D ysfunction. Arterioscler Throm Vasc Biol 1999;19:972-978. Reproduced ${ }^{16}$ with permission.

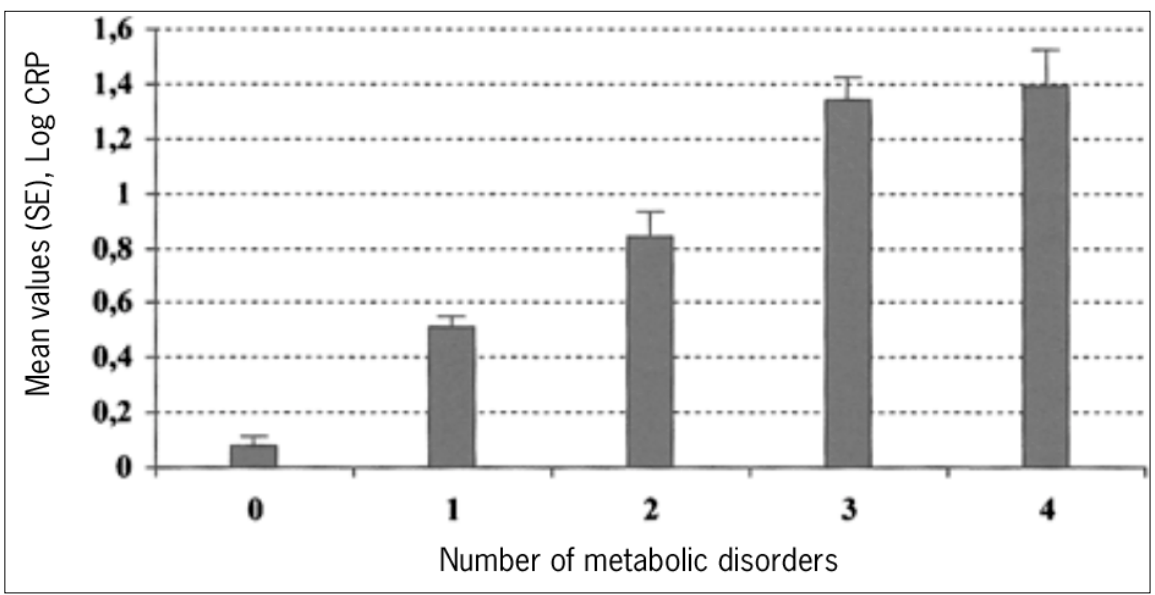

Figure 4. Association of levels of C-reactive Protein with the metabolic syndrome. Festa A, et al. Chronic subdinical inflammation as part of the insulin resistance syndrome. The Insulin Resistance Atherosclerosis Study (IRAS). Circulation 2000;102:4247. Reproduced ${ }^{17}$ with permission.

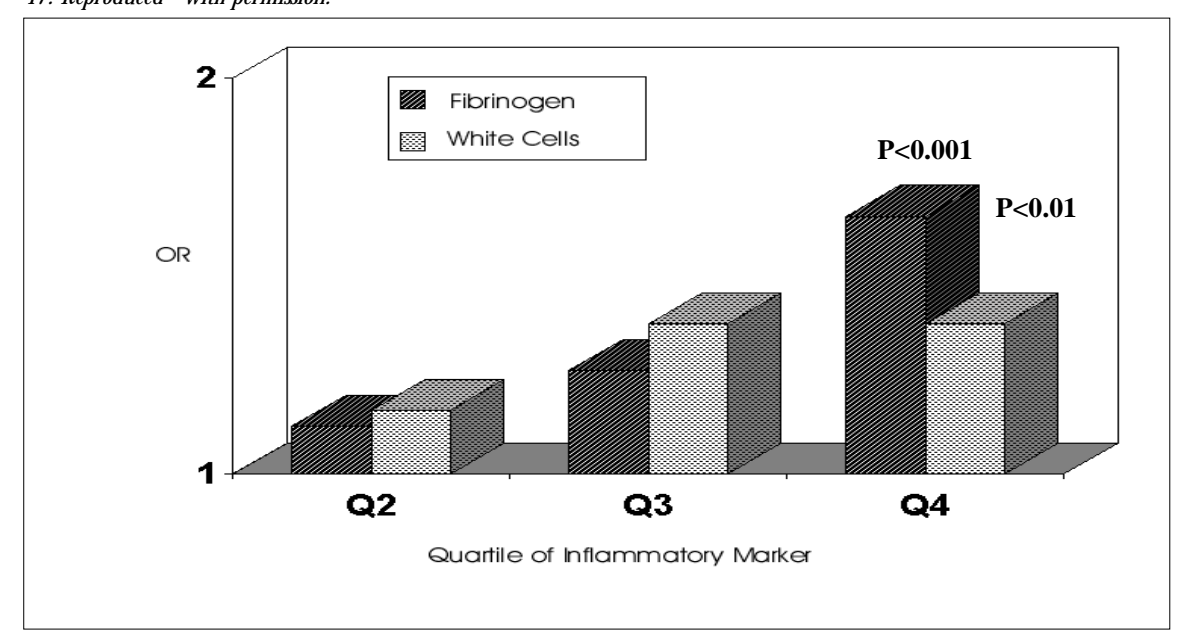

Figure 5. Relative odds of having a major ( $>90 \%$ ile) weight gain over 3 years of follow-up as a function of baseline levels of fibrinogen and white cell count. The Atherosclerosis Risk in Communities Study. 
them, the pro-inflammatory cytokines ${ }^{5}$ tumor necrosis factor-a (TNF-a), interleukin-6 (IL-6) and leptin havereceived greatest attention as links in the disease processes cited above. M ost importantly, activation of this system leads to funda mental changes in body metabolism. ${ }^{24}$

Given an acute infectious stress, the innate system immediately responds with the so-called acute-phase reaction, modulated by cytokines and characterized by a wide range of changes in behavioral function (somnolence), physiology (stimulation of the hypothalamic-pituitary-adrenal axis, increase in catecholamine secretion, leukocytosis), biochemistry (increase in hepatic lipogenesisand adiposetissue lipolysis), and nutritional function (anorexia). ${ }^{25}$ The new state achieved can betransitory in nature, if the precipitating stressisself-limited or treated with success. H owever, if the stressor persists, a chronic, semantically paradoxical "chronic acute-phaseresponse" can result. Characteristics of thischronic state, being more recently noted, are less clear, though they apparently differ from those of the acute state at least in terms of behavioral and nutritional function.

Given theimportant complementary roles of innate immunity and the neuroendocrine system in response to stress, it is important to examine possible interfaces of these systems in the development of the metabolic syndrome. In this regard, Bjorntorp has recently summarized evidence that stress-related hypothalamic arousal, with associated neuroendocrinealterations, particularly perturbations of the hypothalamic-pituitary-adrenal axis, is a major pathway to the metabolic syndrome. Following this theory, daily life stresses would lead to dysregulation of feedback on this axis, with an altered cortisol biorhythm and inhibition of growth hormone and sex hormone production. Concomitantly, the sympathetic nervous system would beactivated. Themetabolic con- sequences suggested include central obesity and insulin resistance. ${ }^{26,27}$ In this regard, it is notable that pro-inflammatory cytokines are major stimulants of the hypothalamic-pituitary-adre nal axis, leading to increased cortisol secretion and inhibition of sex hormone production. ${ }^{28}$

Figure 6 summarizes the systemic actions of relevant cytokines that could contribute to the pathogenesis of the metabolic syndrome, diabetes, and the common causality of diabetes and CHD. Thetheoretical basis of theseinterrelations was recently reviewed. ${ }^{22} \mathrm{~N}$ otable in the figure is that cytokine actions can directly result in insulin resistance, a basic mechanism in the pathogenesis of type 2 diabetes, ${ }^{29}$ as well as producing the dyslipidemic condition typical of thesyndrome ${ }^{30}$ In addition, viaendothelial activation, they could favor vasoconstriction and hemostasis, leading to theinclusion of chronic endothelial activation (endothelial dysfunction) as an integral part of the chronic systemic inflammatory response.

\section{An Integrated Picture: Innate Immunity, Neuroendocrine M odulation, and the Metabolic Syndrome}

Given the above, it is possible to propose that a chronic activation of the innate immune system underlies themetabolic syndrome, aswell as the "common soil" of diabetes and cardiovascular disease. This is illustrated in Figure 7.

The innate immune system, conditioned by genetic factors and immuno-metabolic programming (altered gene expression profile) resulting from fetal and early life stressors, can be activated by a series of insults, including infection, physical trauma and emotional stress. Components of this system, viatheir effectson insulin resistance, ${ }^{29}$ and perhaps also through weight gain ${ }^{21}$ and central obesity, could be basic pathogenic mechanisms for the development and maintenanceof themeta bolic syndrome. Also, as previously mentioned, inflammatory cytokines induce elevation of triglyceridesand reduction of $\mathrm{H} \mathrm{DL}-\mathrm{C},{ }^{30}$ especially when associated with obesity and can produce endothelial activation, with a resulting tendency toward vasoconstriction (hypertension) and hemostatic alterations.

On the other hand, obesity, once present, may reinforce innate immune hyperactivity, as adipose tissue is an important source of pro-inflammatory mediatorssuch as T N F-a, IL-6, and leptin. ${ }^{19}$ T hus, the hyperproduction of so-called adipocytokines and other inflammatory agents, which could well becalled obesitis, could maintain a state of chronic activation of the innate immune system, perpetuating the systemic inflammatory base of the syndrome. In addition, it ispossiblethat insulin resistance, onceinstalled, could also reduce insulin's inhibitory actions in the acute phase $\mathrm{s}^{31,32}$ also favoring maintenance of a chronic state of inflammation.

Thus, as illustrated in Figure 7, depending on genetic predisposition, on the results of earlylife stresses incorporated into expression of this genetic background, and on current lifestyleand environmental factors, this chronic activation of the innate immune system could lead to the de velopment of diabetes and CHD. In this regard, the extent to which, and the pathogenic pathways by which diabetes may independently contribute to cardiovascular disease remain to be es tablished. O nepossibility is that the glycosylation and advanced glycosylation end product (AGEs), caused by hyperglycemiaviatheresulting oxidative stress, $^{33}$ further induce pro-inflammatory cytokines and their deleterious consequences.

CON CLU SION
aggregate in free-living populations. The pro-
spective associations of several inflammatory
markerswith diabetesmellitusand weight gain,
together with cross-sectional data from diverse
populations showing correlations of inflamma

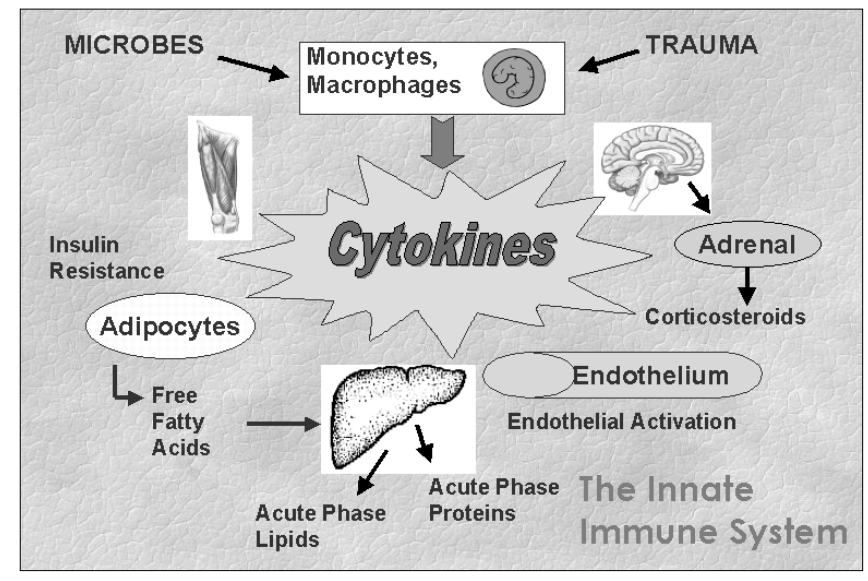

Figure 6. M ajor actions of cytokines in the innate immune system.

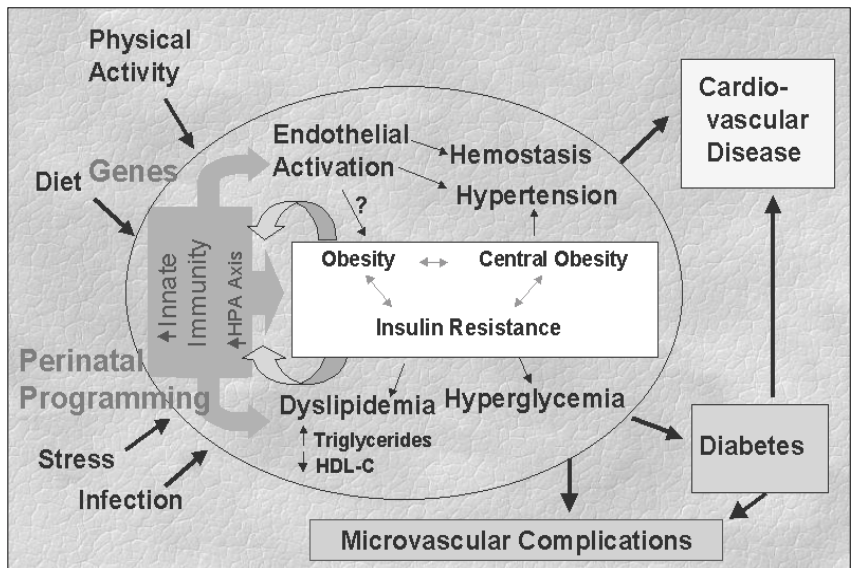

Figure 7. Conceptual framework for understanding the role of the innate immune system in the development of the metabolic syndrome and its complications. 
tory markers with metabolic syndrome components, separately and in aggregate, provide an empirical basis for the hypothesis that a chronic, mild inflammatory state is not only subjacent to cardiovascular disease, but also to this syndrome. Better understanding of the role of theinnateimmunesystem in thepathophysiology of obesity, diabetes, the metabolic syn- drome and cardiovascular disease as well as of the causes of chronic activation of this system may lead to important advances in the prediction and management of thesechronic diseases.
1. Stern M P. D iabetes and cardiovascular disease. The "common soil" hypothesis. Diabetes 1995;44(4):369-74.

2. Reaven GM . Banting Lecture 1988: role of insulin resistance in human disease. Diabetes 1988;37:1595-607.

3. Defronzo RA, Ferranini E. Insulin Resistance: a multifaceted syndromeresponsiblefor N ID D M , obesity, hypertension, dysipidemia, and other atherosclerotic cardiovascular disease. Diabetes Care 1991;14:173-94.

4. Alberti KGM M , Zimmet PZ, for theWH O Consultation. D efinition, diagnosis and classfication of diabetes mellitus and its complications. Part 1: D iagnosis and classification of diabetes mellitus, provisional report of a WH O consultation. Diabet M ed 1998;15:53953.

5. Schmidt M I, Watson RL, D uncan BB, M etcalf P, Brancati FL, Sharrett $A R, D$ avis $C E, H$ eiss $G$, for the ARIC Investigators. Clustering of dysipidemia, hyperuricemia, diabetes, and hypertension and its as sociation with fasting insulin and central and overall obesity in a general population. M etabolism 1996;45(6):699-706.

6. Zimmet PZ, Collins VR, D owse GK, et al. Is hyperinsulinemia a central characteristic of a chronic cardiovascular risk factor clustering syndrome? M ixed findings in Asian Indian, Creole and Chinese M auritians. M auritius N on-communicable D isease Study Group. Diabet M ed 1994;11(4):388-96.

7. Schmidt MI, D uncan BB, Watson RL, Sharrett AR, Brancati FL, $H$ eiss G. A metabolic syndrome in whites and African-Americans. the Atherosclerosis Risk in Communities baseline study. Diabetes Care 1996;19(5):414-8.

8. Ross R. Atherosclerosis. an inflammatory disease N ew Engl J M ed 1999;340(2):115-26.

9. Lindberg G, Lundblad A, Gullberg B, Nilsson-Ehle P, H anson BS. Serum total sialic acid and sialoproten concentration in relation to coronary heart disese risk markers. Atherosclerosis 1993;103:123-9.

10. Lindberg G, Eklund GA, Bullberg B, Rastam L. Serum sialic acid concentration and cardiovascular mortality. BMJ 1991;302:143-6.

11. Ridker PM . Evaluating novel cardiovascular risk factors: $C$ an webetter predict heart attacks? Ann Intern M ed 1999;130:933-7.

12. Saito I, Folsom AR, Brancati FL, D uncan BB, Chambless LE,

.. Pụbl ish ing in in or mat ion.

Bruce Bartholow Duncan, MD, PhD. Social Medicine Department, School of M edicine, Universidade Federal do Rio G rande do Sul, Porto Alegre, Brazil.

Maria Inês Schmidt, MD, PhD. Social Medicine Department, School of Medicine, Universidade Federal do Rio $G$ rande do Sul, Porto Alegre, Brazil.

Sources of funding: Projeto de $N$ úcleos de Excelência (PRO N EX) Grant 661041/1998-0 and a Bristol-Myers Squibb Foundation Better Health for W omen $\mathrm{G}$ rant

\section{Conflict of interest: $\mathrm{N}$ one}

Last received: 22 December 2000

Accepted: 03 January 2001

\author{
Address for correspondence \\ Bruce Bartholow Duncan \\ PPG Epidemiologia da Faculdade de Medicina da \\ Universidade Federal do Rio Grande do Sul \\ R. Ramiro Barcelos, 2600/414, \\ Porto Alegre/ RS - Brazil - CEP $90035-003$ \\ E-mail: bbduncan@orion.ufrgs.br
}

M CG overn PG. Nontraditional risk factors for coronary herrt disease incidence among persons with diabetes the Atherosderosis Risk in Communities (ARIC) Study. Ann Intern M ed 2000;133(2):81-91.

13. Duncan BB, Schmidt MI, O ffenbacher S, Wu KK, SavagePJ, H eiss G. Factor VIII and other hemostasis variables are related to incident diabetes in adults: the Atherosclerosis Risk in Communities (ARIC) Study. Diabetes Care 1999:22(5):767-72

14. Schmidt MI, D uncan BB, Sharrett AR, et al. M arkers of inflammation and prediction of diabetesmellitusin adults (Atherosclerosis Risk in Communities study): a cohort study. Lancet 1999;353:1649-52.

15. Pickup JC, M attock M B, Chusney GD, Burt D. NID D M as a dis ease of the innate immune system: association of acute phase reactants and interleukin- 6 with metabolic syndrome X. Diabetologia 1997;40:1286-92

16. Yudkin JS, Stehouwer CD A, Emeis|J, Coppack SW. C-reactiveprotein in healthy subjects: association with obesity, insulin resistance, and endothelial dysfunction. Arterioscler Thromb Vasc Bio 1999;19:972-8.

17. FestaA, D 'Agostino RB, H oward G, M ykkanen L, Tracy RP, $H$ affne SM . Chronic subclinical inflammation as part of the insulin resistancesyndrome Thel nsulin ResistanceAtherosclerosisStudy (IRAS) Circulation 2000;201:42-7.

18. M orangePE, Alessi M C, Verdier M, CasanovaD , M agalon G, JuhanVaguel. PAI-1 produced ex vivo by human adiposetissueis relevant to PAl-1 blood level. Arterioscler Thromb Vasc Biol 1999;19(5):1361-

19. Funahashi T, NakamuraT, Shimomura K, M zeda K, Kuriyama H Takahashi M , AritaY, KiharaS, M atsuzawaY. Roleof adipocytokines on the pathogenesis of atherosclerosis in visceral obesity. Intern M ed 1999;38:202-6

20. M ohamed-AliV, GoodrickS, Rawesh A, KatzD R, M ilesJM, Yudkin JS, Klein S, Coppack SW. Subcutaneous adipose tissue releases interleukin-6, but not tumor necrosis factor-alpha, in vivo. J Clin Endocrinol M etab 1997;82(12):4196-200.

21. Duncan BB, Schmidt MI, Chambless LE, Folsom AR, Carpente $M, H$ eiss $G$, for the ARIC Investigators. Fibrinogen, other putative markers of inflammation and weight gain in middleaged adults TheARIC Study. O besity Res 2000;8(4):279-86

22. Pickup JC, Crook M A. Is type II diabetes mellitus a disease of the innate immune system? D iabetologia 1998;41(10):1241-8.

23. Fearon DT, Locksley RM. The instructive role of innate immunity in the acquired immune response. Science 1996;272:50-3.

24. Memon RA, Feingold KR, Grunfeld C. Cytokines and intermediary metabolism. In: Remick D G, Friedland JS, editors. Cytokines in health and disesese. 2nd edition. N ew York: M arcel D ekker; 1997:38199.

25. Kushner I, M ackiewicz $A$. The acute phase response: an overview. In: M ackiewicz A, Kushner I, Baumann $\mathrm{H}$, editors. Acute Phase Proteins: M olecular Biology, Biochemistry, and Clinical Applications Boca Raton: CRC Press; 1993:4-19.

26. Bjorntorp P, Rosmond R. The metabolic syndrome a neuroendocrine disorder? Br J Nutr 2000;83(Suppl 1):S49-S57.

27. Bjorntorp P, Rosmond R. N euroendocrine abnormalities in viscera obesity. Int I O bes Relat M etab D isord 2000;24(Suppl 2):S80-S85.

28. Reichlin S. Neuroendocrinology. In: Reichlin S, Wilson JD Foster D W, K ronenberg H M , Larsen PR, editors. WilliamsTextbook of Endocrinology. 9th ed. Philadelphia: W B Saunders C 0 . 1998:165-248.

29. H otamisigil GS. M echanisms of T N F-a induced insulin resistance Exp Clin Endocrinol Diabetes 1999;107:119-25

30. KhovidhunkitW, M emon RA, Feingold KR, Grunfeld C. Infection and inflammation-induced proatherogenic changes of lipoproteins J Infect Dis 2000;181(Suppl 3):S462-S472.

31. Campos SP, Baumann H Insulin is a prominent modulator of the cytokinestimulated expression of acute phase plasma protein genes Molec Cell Biol 1992;12(4):1789-992.

32. M elidonis A, Stefanidis A, Tournis S, et al. The role of strict meta bolic control by insulin infusion on fibrinolytic profile during an acute coronary event in diabetic patients. Clin Cardio 2000:23(3):160-4

33. Ceriello A. H yperglycemia: the bridge between non-enzymatic glycation and oxidative stress in the pathogenesis of diabetic complications. Diabetes Nutr M etab 1999;12(1):42-6.
CONTEXTO : A síndrome metabólica se caracteriza por um agrupamento, em populações, de fatores de risco para doenças cardiovasculares ediabetes geralmenteligados à resistência à insulina, à obesidade e à obesidade central. Consonante com a patogênese inflamatória bem-estabelecida da doença aterosclerótica, a síndromemetabólica está agora sendo pesquisada em relação à sua natureza inflamatória.

O BJETIVO: A presentamos dados transversais demonstrando que marcadores de inflamação se correlacionam com componentes da síndrome metabólica, e dados prospectivos do Estudo ARIC indicando que marcadores de inflamação e de disfunção endotelial predizem o desenvolvimento de diabetesmellituse ganho de peso em adultos. Apresentamos evidências biológicas que sugerem que a ativação crônica do sistema imune inato pode ser a base da síndrome metabólica, caracterizando o solo comum para a causalidade do diabetes mellitus tipo 2 e da doença cardiovascular.

CONCLUSÕES: 0 melhor entendimento do papel do sistema imune inato nessas doenças poderá levar a avanços importantes na predição e manejo do diabetes e da doença cardiovascular.

PALAVRAS CH AVES: Inflamação. Citocina. Diabetes não insulino dependente. D oença Cardiovascular. $O$ besidade. Síndrome $X$. 